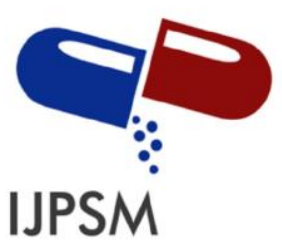

Wenny Sri Agung et al, Int. Journal of Pharmaceutical Sciences and Medicine (IJPSM),

Vol.6 Issue. 1, January- 2021, pg. 31-39

ISSN: 2519-9889

Impact Factor: 3.426

\title{
REVIEW: Increased Dissolution Rate Ofloxacin in Solid Dispersion Systems
}

\author{
Wenny Sri Agung ${ }^{1}$; Rina Wahyuni ${ }^{1}$; Maria Dona Octavia ${ }^{1}$; Harrizul Rivai ${ }^{\mathbf{2}^{*}}$ \\ ${ }^{1}$ College of Pharmacy (STIFARM), Jl. Raya Siteba Kurao Pagang, Padang 25147, Indonesia \\ ${ }^{2}$ Faculty of Pharmacy, Andalas University, Limau Manih Campus, Padang 25163, Indonesia \\ "Email: harrizul@yahoo.co.id and harrizul@phar.unand.ac.id \\ DOI: 10.47760/ijpsm.2021.v06i01.003
}

\begin{abstract}
Ofloxacin (OFX) is a broad-spectrum fluoroquinolone group antimicrobial, including the second-generation fluoroquinolone class of antibiotics, which is very effective against gram-positive and gram-negative bacteria. This compound has a low level of solubility in the small intestine's pH conditions, so it requires increased solubility and dissolution with a solid dispersion system. Several methods and chemical additives have been used to improve the dissolution rate of Ofloxacin. This review article analyzed literature studies on the increase in dissolution rate of Ofloxacin in a solid dispersion system. We carried out the literature review through a search with Google Scholar. The analysis showed that from several methods, it was found that the ternary system with surfactant enhancer in the form of Sodium Laurier Sulfate and other surfactants could increase the dissolution rate of Ofloxacin.
\end{abstract}

Keywords: Dissolution Rate, Ofloxacin, Solid Dispersion System

\section{Introduction}

The dissolution rate or the speed of dissolving drugs relatively insoluble in water is a big problem in the pharmaceutical industry. In general, these drugs undergo a slow dissolution process as well as their absorption rate. In this case, the dissolved drug particles will be absorbed in a low rate or even not completely absorbed so that the drug's absorption is incomplete. [1] More than $80 \%$ of drugs on the market are in tablet form, and $40 \%$ of these drug compounds have low water solubility. Nearly $80-90 \%$ of compounds in drugs in the research stage also have solubility and dissolution rates. [2]

A preparation before being absorbed in the blood, other body fluids, and tissues must first dissolve. Drug solubility is the initial process that occurs in the digestive juices before the drug substance is absorbed in the drug absorption site. For a preparation with a high level of solubility, the dissolution rate of the active substance from the dosage form will be faster. On the other hand, a preparation with a low dissolution rate means that the dissolution rate of the active substance from the dosage form will be slower. The drug absorption rate is slower and results in low bioavailability. [3]

The dissolution rate is the total active substance that dissolves over time under standardized conditions from the surface of the liquid or solid, temperature, and composition of the solvent per time. The dissolution rate can be a speed limiting step before the active drug substance enters the blood. [4] The dissolution rate-limiting factors include formulation, excipients, fillers, disintegrants, granulating agent, binder, tablet coating effect, pressing effect, processing factor effect, solubility, particle size, formulation, physicochemical effect, crystalline state salt formation, and others. It is a matter that is still complicated because the removal of the active solid substance from the delivery system (its dosage form) involves a sequential process starting from disintegration, degradation into small particles, to the dissolution of particles. The process uses a different percentage of the total time required for the active dissolved substance, and each of these processes is a speed limitation, depending on the total time used. [4] 


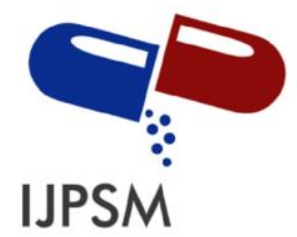

\section{$1^{\text {st }}$ Author et al., Int. Journal of Pharmaceutical Sciences and Medicine (IJPSM), Vol.1 Issue. 1, December- 2016, pg. 1-4}

Ofloxacin is a broad-spectrum fluoroquinolone antibiotic, making it effective against gram-positive and gramnegative bacteria. [5] Ofloxacin is well absorbed in the gastrointestinal tract and has nearly 100\% bioavailability and a peak plasma concentration of about 3-5 micrograms / $\mathrm{mL} 1$ to 2 hours after oral administration. [6] Ofloxacin is more soluble at acidic $\mathrm{pH}$ (gastric environment) and slightly soluble at neutral $\mathrm{pH}$ or alkaline $\mathrm{pH}$ (intestinal environment). [7]

Ofloxacin has the chemical name 9-fluoro-2,3-dihydro-3-methyl-10- (4-methyl-1-piperazinyl) -7-oxo-7Hperiod [1,2,3-de] [1,4 ] benzoxazine-6-carboxylic acid with the molecular formula C18H20FN3O4. Ofloxacin is one of the fluorinated quinolones. This drug is administered orally and is broad-spectrum antibacterial, active against most Gram-negative bacteria, many Gram-positive bacteria, and some anaerobes. The chemical structure of Ofloxacin is shown in Figure 1. [8]<smiles>CC1COc2c(N3CCN(C)CC3)c(F)cc3c(=O)c(C(=O)O)cn1c23</smiles>

Figure 1: Structure of Ofloxacin Hydrochloride. [8]

The mechanism of action of Ofloxacin is by inhibiting the enzyme DNA topoisomerase (ATP-hydrolyzing), a type II DNA topoisomerase known as DNA gyrase. The target of Ofloxacin is the A subunit of the enzyme. DNA gyrase inhibition in sensitive organisms results in inhibition of the ATP-dependent DNA negative screening process and promotion of DNA double-chain breaking. Ofloxacin differs from other quinolones in that it has an additional mechanism of action independent of RNA and protein synthesis. The antibacterial activity of Ofloxacin is not affected by bacterial resistance to antibacterials other than quinolone, but its exercise is significantly reduced in acidic urine. [8]

The solid dispersion method is a modification of medicinal substances by dispersing drug substances that are difficult to dissolve in water into a soluble carrier to reduce the particle size or attempts to form polymorphs soluble. [8] Solid dispersion is a product that consists of at least two different components, namely hydrophobic active ingredients and hydrophilic matrices, where the active ingredients will turn into crystalline, dissolved, or amorphous. [9]

\section{Data Collection}

In compiling this review article, the technique used is to use literature studies by finding sources or literature in primary data, official books and international journals, and national journals. In this review article, data search also uses online media with Ofloxacin, Dissolution Rate, and Solid Dispersion System. Search for the primary references used in this review article through trusted websites such as ScienceDirect, NCBI, ResearchGate, Google Scholar, and other journals published and can be trusted.

\section{Results and Discussion}

Based on the data obtained from the results of literature search, it is found that in the research conducted by De K Pintu, et al., the aim of which is to see an increase in the dissolution rate of Ofloxacin by making the drug molecule dispersion in the polymer matrix of Polyethylene Glycol-6000. Ofloxacin solid dispersion is prepared after fusion and evaporation technique. In the manufacture of Ofloxacin Solid Dispersion using two methods, namely the Hot Melt method and the solvent evaporation method. In the hot melt method, Ofloxacin and PEG6000 were mixed with different compositions ( $10 \& 20 \%$ drug content). Then melted in a container with a temperature of $257^{\circ} \mathrm{C}$ cooled in a refrigerator. In the evaporation method, it is dissolved jointly between drug, Ofloxacin and polymer, Polyethylene glycol 6000 (PEG 6000) in a common solvent, namely chloroform. After solvent evaporation, the formula is stored in a desiccator containing active silica gel and dried to constant weight. The dry product has become powder sieved through sieve no.100 and stored in a desiccator for further evaluation use. In the drug-polymer compatibility study, the physicochemical interaction between Ofloxacin and polymer (PEG 6000) used in the solid dispersion formulation was studied using Fourier transform infrared spectroscopy (FTIR). Infrared spectra were recorded in a FTIR (Perkin Elmer) instrument in a long region 


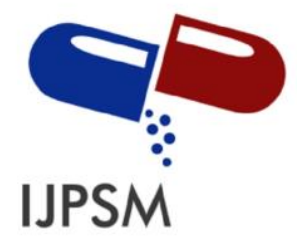

\section{$1^{\text {st }}$ Author et al., Int. Journal of Pharmaceutical Sciences and Medicine (IJPSM), Vol.1 Issue. 1, December- 2016, pg. 1-4}

wave between 4400 and $600 \mathrm{~cm}-1$ by the $\mathrm{KBr}$ pellet method. The analysis results revealed that the solid dispersion of Ofloxacin can be prepared with Polyethylene Glycol 6000 by both Fusion and the solvent evaporation technique can increase the dissolution rate of Ofloxacin. Drug stability, ofloxacin was not affected by either of the two methods and the formulation could be stored without significant degradation in the long term. Among the two methods that have been carried out, the highest dissolution was found with the formulations prepared by the evaporation technique and the addition of surfactants. It can be concluded that the formulation and manufacturing process can affect the dissolution and bioavailability of the drug by the dispersion of drug molecules in the polymer matrix of Polyethylene Glycol-6000 by the evaporation method. With the addition of surfactants, the dissolution rate oflixacin solid dispersion showed an increase. After 15 minutes, only $65 \%$ of the pure drug was dissolved in the water medium while at the same time $98 \%$ dissolution occurred with a solid dispersion formulation with the addition of a surfactant. [10]

Research conducted by Okonogi Siriporn and Puttipipatkhachorn Satit, aims to investigate drugs with high solid dispersion systems consisting of drugs, carriers and surfactants. This study used Ofloxacin, polyethylene glycols (PEG) of various molecular weights (PEG 4000 and PEG 20000), Polysorbate 80, liquid nonionic surfactants with hydrophilic-lipophilic balance (HLB) and other chemicals from the class of analytic reagents. Solid dispersion of water-insoluble ofloxacin (ofloxacin) with polyethylene glycol (PEG) with different molecular weight for binary solid dispersion systems as drug carriers with a ratio of not less than 5: 5.Polysorbate 80, a nonionic surfactant is introduced into the binary solid dispersion system as the third component to obtain a ternary solid dispersion system. The dissolution rates of Ofloxacin OFX from binary and ternary solid dispersions were investigated using a modified USP rowing method with a rotating speed of $100 \mathrm{rpm}$. The sample powder containing $100 \mathrm{mg}$ ofloxacin was compressed from 2 tonnes / cm2 into flat surface tablets of $10 \mathrm{~mm}$ in diameter. The tablet is placed in the bottom of a beaker containing $1000 \mathrm{~mL}$ of distilled water as a medium with a temperature of 370C. The dissolution behavior of ofloxacin from binary ofloxacin and ternary solid dispersion with PEG 4000 or PEG 20000 in comparison with the whole drug was examined by plotting the percentage of drug released against time. The analysis showed that the dissolution rate of the ternary solid dispersion system drug was higher than the binary solid dispersion system, namely the ternary solid dispersion containing OFX / PEG 4000 / Tween 80 from 5: 5: 1 wt / wt / wt. In the ternary system, the influence of the molecular weight of PEG and Tween 80 is clearly visible. The lower the molecular weight of the PEG, the higher the dissolution rate. Tween 80 plays an important role in drug dissolution from the ternary system. This occurs because it improves the dispersion of drug molecules in the polymer matrix and the drug becomes wetter and dissolves easily so that it dissolves the non-molecularly or crystalline dispersed OFX fraction. In the proportion of ternary solid dispersion, it was found that more than $65 \%$ of the drug was dissolved in 30 minutes with an initial dissolution rate of $2.18 \% / \mathrm{min}$, above a 36 -fold increase in the dissolution rate of the whole drug. [11]

Research conducted by Srikanth et al., aims to formulate and evaluate a gastroretentive floating drug delivery system. Ofloxacin is made using natural and synthetic polymers such as gum karaya (GK) and polyethylene oxide (PEO) using effervescent floating techniques. The formulation is made by wet granulation technique and sodium bicarbonate $(10 \% \mathrm{w} / \mathrm{w})$ is combined as a gas producing agent. Tablets were evaluated for hardness, in vitro buoyancy, drug content and in vitro drug release studies. The data obtained were analyzed using different mathematical models, namely - zero order flux, first order, erosion plots, Higuchi and Korsmeyer Peppas equations. From a number of tablet formulas regardless of the polymer used, the hardness and friability values were $>5.0 \mathrm{~kg} / \mathrm{cm} 2$ and $<0.68 \%$. The total in vitro lag time and buoyancy time for all formulations were between 45 to 183 seconds and 5 to 16 hours, respectively. The results of the in vitro buoyancy study showed that the floating time lag of the formulations prepared with PEO was between 45 to 92 seconds formulated with Gum Karaya (GK) between 115 to 183 seconds. This results in a dissolution rate of the medium $(0.1 \mathrm{~N}$ $\mathrm{HCl})$ into the matrix formulation, which results in free carbon dioxide as carbonate and bicarbonate interacting with the acid medium. When the polymer concentration in the formulation increases, drug release decreases. The gastroretentive floating drug delivery system against ofloxacin using synthetic polymers (polyethylene oxide) and natural polymers (gum karaya) with drug to polymer ratios of 1: 0.5 and 1: 0.625 , respectively, was the final optimized formulation. [11]

Sarita and Jaya's research on the preparation and evaluation of solid dispersion ofloxacin. In this study the solid dispersion ofloxacin was prepared by a physical mixture method. The dispersion was studied for drug polymer 


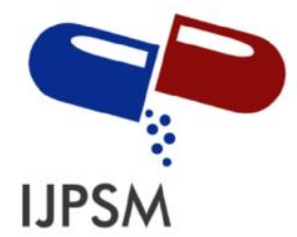

\section{$1^{\text {st }}$ Author et al., Int. Journal of Pharmaceutical Sciences and Medicine (IJPSM), Vol.1 Issue. 1, December- 2016, pg. 1-4}

compatibility, characterized for its powder mix properties and in vitro drug release studies. Various types of polymers are used, namely the PEG and Urea poloxomers for the manufacture of solid dispersions ofloxacin. The in vitro release profile of the solid dispersion ofloxacin indicates that the formulation contains a patternxomer (F8) comprising a drug: polymer ratio of 1: 1 indicating a satisfactory drug release of $98 \%$ at the end of 45 minutes among all formulations. [12]

Research by R Happy Prima, et al. on the physicochemical characteristics of the solid dispersion of ofloxacin with PEG 6000 carrier in binary and ternary systems. This study used a ternary system solid dispersion formula based on a 23 factorial design with a carrier composition of polyethylenglycol 6000 (PEG 6000), a composition of sodium lauryl sulfate (SLS) and a method of preparation (physical mixture and solvent evaporation). Dissolution efficiency at 60 minutes. The materials used were Ofloxacin, Sodium lauryl sulfate, Polyethylenglycol 6000. The OFX solid dispersion ternary system was prepared using a 23 factorial design (3 factors and 2 levels), where the optimized factor was, X1: the number of soluble carriers. water PEG 6000 (250-350mg), X2: total surfactant SLS (25-75mg) and X3: method of making solid dispersions (physical mixing-solvent evaporation). A solid dispersion binary system was prepared without the addition of surfactants (for comparison). Preparation of OFX Solid Dispersion a. Physical mixture method: An amount of OFX and a carrier is included in the mortar. The mixture was prepared by simple trituration in a porcelain mortar, then sieved with a mesh no.44 sieve and stored in a desiccator until further studies. b. Solvent evaporation method: An amount of OFX and a carrier is dissolved in a certain solvent with the help of a stirrer. The solvent is evaporated at $45^{\circ} \mathrm{C}$ until constant weight is achieved. This mass was powdered and sieved with a mesh sieve no. 44 and stored in a desiccator until further studies. The analysis showed that the solid dispersion of ofloxacin by solvent evaporation method showed higher solubility and dissolution than pure ofloxacin and its physical mixture. In the ternary system, the addition of SLS surfactants provides a greater increase in dissolution, and the solvent evaporation method provides maximum results compared to physical mixing. At 60 minutes, the ternary mixture using the PEG 6000-SLS carrier produced a much larger percent of the drug dissolved, namely $102.249 \%$. This condition indicates that Sodium Lauryl Sulfate (SLS) is used as the third component in the ternary system because it has good solubilizing action for some drugs. [13]

Okonogi et al. conducted research on the effect of carrier type on physicochemical properties and ofloxacin solids dissolution. This study used Ofloxacin, Chitosan with an $85 \%$ degree of deacetylation, Polyethylene glycol (PEG) with different molecular weights (PEG 4000 and PEG 20000) and polyvinylpyrrolidone (PVP) K-90 and all other chemicals are of analytical grade. Solid dispersions ofloxacin (OFX) and a number of carriers including chitosan and water-soluble polymer polyethylene glycol (PEG) 4000, PEG 20000, and polyvinylpyrrolidone K-90 are prepared by the solvent evaporation method to improve drug dissolution. The dissolution test results showed that the dissolution rate of OFX was significantly increased in the solid dispersion system compared to the pure drug. The results also showed that the increase in the dissolution rate was higher when the carrier weight fraction increased. The effect of the molecular weight of PEG on the dissolution of OFX was also observed. In solid dispersions with a 1: 9 ratio of drug to carrier, PEG 4000 provides the highest drug dissolution rate, whereas at 1: 1 ratio, chitosan appears to be the best carrier for drug release. It was concluded that chitosan could be the carrier of choice for increased dissolution in solid dispersions with high drug content. [14]

Urbaniak et al. conducted research on the Study of Enantiomeric Ofloxacin from Selected Solids Using High Performance Capillary Electrophoresis Method. This study aims to determine the dissolution rate kinetics of the optical isomer of ofloxacin (S - (-) and R - (+) - ofloxacin) from solid oral dosage forms using the flow cell method (USP method 4). The reagents used in this study were Levofloxacin, Ofloxacin (OFX), hydroxypropyl$\beta$-cyclodextrin (HP- $\beta-\mathrm{CD}$ ) and sodium phosphate monobasic dihy-drate, hydrochloric acid ( $\mathrm{HCl} 0.1 \mathrm{M} / \mathrm{L})$ and phosphate dissolution buffer $\mathrm{pH} 6.8$ concentrates. obtained from POCh. All solutions used during the presented studies were prepared using deionized water by the Millipore Simplicity System. The concentrations of analytes (racemic ofloxacin and their enantiomers) in tablet extract samples as well as in dissolution media (0.1 $\mathrm{M} / \mathrm{L} \mathrm{HCl}$ and phosphate buffer $\mathrm{pH}$ 6.8) were determined by a valid high performance capillary electrophoresis method. Similar results were observed for Ofloxacin-Ratiopharm and Tavanic tablets examined in phosphate buffer (mean fraction was about $100 \%$ after 30 minutes), whereas in the case of Tarivid and OfloHexal the mean fraction of the determined dose in buffer $\mathrm{pH} 6.8$ was $14 \%$ and $44 \%$, respectively. The 


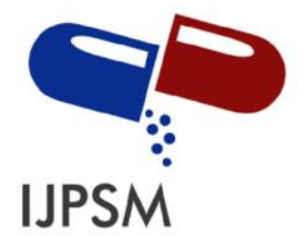

\section{$1^{\text {st }}$ Author et al., Int. Journal of Pharmaceutical Sciences and Medicine (IJPSM), Vol.1 Issue. 1, December- 2016, pg. 1-4}

dissolution data obtained for phosphate buffer $\mathrm{pH} 6.8$ showed that Ofloxacin-Ratiopharm and Tavanic tablets released more than $75 \%$ of the active substance after 30 minutes. [15]

Research by Mistry et al. about the formulation and in vitro evaluation of ofloxacin tablets using natural gum as a binder. In this research, efforts have been made to make Ofloxacin tablets using three natural binders, namely Acacia arabica, Hibiscus esculentus, and xanthan gum. The six batches of Ofloxacin tablets were prepared using various types and quantities of natural binders using the wet granulation method. Tablets were analyzed for hardness, brittleness, and weight variation, and in vitro release was carried out in a phosphate buffer at $\mathrm{pH}$ 6.8. The prepared tablets were also evaluated for various release kinetics and similarity factor f2. The dissolution rate of Ofloxacin from various tablets was studied using the six-station dissolution assay USP XXIII. The dissolution rate was studied by placing one tablet containing $300 \mathrm{mg}$ Ofloxacin in $900 \mathrm{ml}$ of phosphate buffer pH 6.8 maintained at $37 \pm 0.50 \mathrm{C}$ at $50 \mathrm{rpm} .5 \mathrm{ml}$ samples were taken at different time intervals, filtered (albeit $0.45 \mu \mathrm{m}$ ), and replaced with $5 \mathrm{ml}$ of fresh dissolved media. The samples were diluted properly and estimated spectrophotometrically at $207 \mathrm{~nm}$ using ELICO dual-beam UV spectrophotometry. The dissolution test results indicated that the drug release profiles were similar, although the type of binder and the physicochemical characteristics of the excipients varied. All batches showed a better drug release profile and showed more than $85 \%$ within 45 minutes of tablets prepared using different types and amounts of binders. It was found that drug release decreased with increasing gum concentration. [16]

Research by Khalid et al. on Post Market Supervision Various Brands of Ofloxacin $200 \mathrm{Mg}$ Tablets Available in Karachi (Pakistan) Local Market. This study aims to compare the dissolution profile of ofloxacin tablets $(200 \mathrm{mg}$ ) and to test the feasibility of biowaiver studies without carrying out bioavailability studies to achieve the specified drug quality. This research method evaluated the six brands ofloxacin $200 \mathrm{mg}$ tablets that were evaluated using several quality control parameters, such as weight variation, hardness, disintegration and dissolution tests in order to assess the bioequivalence. Dissolution tests are carried out in accordance with FDA requirements for all brands that require biowaivers. Ofloxacin tablets were evaluated in $900 \mathrm{ml}$ buffer $\mathrm{pH} 1.2$, 4.5 and 6.8 using the US Pharmacopoeia dissolution apparatus II (USP-32). Most products can be considered to dissolve very quickly because more than $85 \%$ of the labeled medicinal substance dissolves within 15 minutes. These results indicate that the design of the formulation and / or manufacturing process affects the dissolution and bioavailability of the drug product so that when formulated correctly, Ofloxacin reaches its absorption site in solution form. [17]

Research conducted by Babu et al. outlines a systematic approach for designing and developing Ofloxacin floating tablets to improve the bioavailability and therapeutic efficacy of the drug. The materials in this study were Ofloxacin, HPMC K100M, Carbopol 934P and Gum Karaya. All other chemicals are of analytical grade. The floating tablets were evaluated for uniform weight, hardness, brittleness, drug content, in-vitro buoyancy, swelling index studies, dissolution studies and stability studies. In-vitro dissolution studies of all ofloxacin formulations were carried out in $0.1 \mathrm{~N} \mathrm{HCl}$. The study was carried out over 24 hours, and the cumulative drug release was calculated at different time intervals. Short-term stability studies of the OH5, OHK3 and OHKC1 optimized formulations showed that there were no significant changes in drug levels and dissolution parameter values after 3 months of storage at $40 \pm 2^{\circ} \mathrm{C}$. [18]

Research by Saigeethika $\mathrm{et} \mathrm{al}$. about the formulation and evaluation of the floating table ofloxacin. The release rate of ofloxacin from floating tablets was determined using a dissolution assay. USP II apparatus (paddle method. The dissolution test was performed using $900 \mathrm{~mL}$ buffer $\mathrm{pH} 1.2$, at $37 \pm 0.5^{\circ} \mathrm{C}$ and $50 \mathrm{rpm} .10 \mathrm{ml}$ samples were withdrawn from the dissolving apparatus at regular time intervals of up to 24 hours. Then and diluted to a concentration corresponding to $\mathrm{pH} 1.2$ buffer. The sample is replaced with fresh dissolving medium of the same volume in a basket. The absorbance of this solution is measured at $294 \mathrm{~nm}$ using a UV / VIS spectrophotometer (JASCO). The cumulative drug release percentage is calculated using the equation obtained of the standard curve $y=0.094 x+0.017$ The results of the analysis showed that sufficient drug release from the tablet was maintained for 24 hours and the non-fickian transport of the drug from the tablet was confirmed. It appears that drug release appears to be a complex mechanism of inflammation, diffusion, and erosion. [19]

Research by Baddam et al. about the formulation and evaluation ofloxacin tablets quickly dissolves by the correct compression method. The purpose of this study was to formulate and evaluate the dissolution rate of ofloxacin tablets by direct compression method using different super disintegrants such as PGS (Pre 


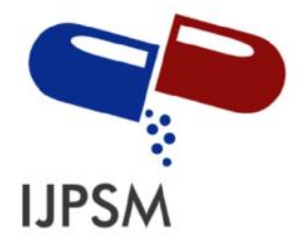

\section{$1^{\text {st }}$ Author et al., Int. Journal of Pharmaceutical Sciences and Medicine (IJPSM), Vol.1 Issue. 1, December- 2016, pg. 1-4}

Gelatinized Starch), SSG (Sodium Starch Glicolate), PVPP (Poly Vinyl Poly Pyrolidone) at different concentrations of 5\%,7\%., 10\%. FT IR spectroscopy was used to determine the physical characteristics of the complex. Mixtures were evaluated for angel of repose, bulk density, tapped density, carr s index, hausner ratio. Tablets were evaluated for variations in weight, hardness, brittleness, disintegration time, water absorption ratio, wetting time, uniformity of drug ingredients and in vitro dissolution. Tablets formulated with $10 \%$ PVPP showed low disintegration time $(8+\ldots 2)$, wetting time $(4,3-0.3)$, the fragility compared to batch orders. \% The cumulative release of drug from tablet F9 was found to be more than $87 \%$ in 10 minutes. [20]

Research conducted by Awofisayo et al. challenge Comparative Assessment of Quality Control Measurement of Multisource Ofloxacin Tablets Marketed in Nigeria. This study evaluated several quality control parameters to compare the quality, safety and efficacy of nine brands ofloxacin tablets available in the Nigerian Market. The physicochemical parameters and test of the nine ofloxacin tablet brands were assessed by evaluating the uniformity of tablet weight, brittleness, hardness, disintegration, and testing of active ingredients according to the established method. The dissolution rate and disintegration time were determined in simulated gastric fluid (SGF) and simulated intestinal fluid (SIF) without enzymes. The concept is Dissolution Efficiency (DE) and Predicted Availability Equivalence (PAE) are used to estimate the in vivo probability of bioavailability. All brands meet official specifications for uniformity in weight, brittleness and disintegration. The disintegration test revealed that the drug had a higher disintegration time at SGF (7.0 \pm 0.95$)$ compared to the drug at SIF (5.0 \pm 2.55 ). The dissolution profile in SGF shows that only one sample achieved $70 \%$ dissolution in less than 45 minutes and 5 other samples in 1 hour, whereas in SIF, four samples achieved 70\% dissolution in 45 minutes and all samples in 1 hour. Only the four brands considered in this study showed quality that was up to the standard. This method is simple and crude for routine analysis and evaluation of the dissolution pattern of ofloxacin tablets as an in vitro test for batch-to-batch quality control assessments. [21]

Research by Singh Virender et al. regarding the in-vitro quality assessment of various marketed brands ofloxacin tablets. Various evaluation tests were performed on the selected ofloxacin bands to compare their quality characteristics. Drug product dissolution testing is an important criterion in assessing in vitro drug release information for quality control purposes as well as in drug development. This test describes the overall rate of the process involved in releasing the drug into a bioavailable form. Variation in drug release among generic drugs indicates deficiencies in all drug formulations and delivery systems. Dissolution tests are performed using the Erweka dissolution instrument. The paddle method was used at $50 \mathrm{rpm} .0 .1 \mathrm{~N}$ chloride acid $(900 \mathrm{ml})$ was prepared as the dissolution medium. $0.1 \mathrm{~N}$ hydrochloric acid $(900 \mathrm{ml})$ was prepared as a dissolution medium, poured into a vessel and equalized to $37 \pm 0.5^{\circ} \mathrm{C}$. Six tablets from each brand were randomly selected and one tablet was inserted into each apparatus compartment containing $1000 \mathrm{ml}$ of media at $37 \pm 0.5^{\circ} \mathrm{C}$. Ten milliliters of sample were taken at intervals of $5,10,15,30,45,60$ minutes with a $10 \mathrm{~mL}$ pipette and a new $10 \mathrm{ml}$ dissolution medium was replaced after each sampling to maintain sink conditions. Each sample taken was filtered and the filtrate was further diluted and the absorbance was measured at $233 \mathrm{~nm}$ against the dissolution medium using UV spectrophotometry. Dissolution test results showed that more than $75 \%$ of the drug was released in 30 minutes and more than $96 \%$ in 120 minutes. This shows that the drug is in accordance with the official regulations and it can be ascertained that these drugs can be used interchangeably even though they are manufactured by different companies. [22]

Research conducted by Gangurde et al. about the formulation and evaluation of the continuous release ofloxacin bioadhesive tablets using 32 factorial designs. This study aims to design a continuous release bioadhesive bioadhesive dosage form ofloxacin. 32 complete factorial designs were used to systematically study drug release profiles and bioadhesive strength. Carbopol 934P and HPMC K100M were chosen as independent variables. Compatibility between drugs and polymers was tested by using Fourier transform infrared (FTIR) and X-ray diffraction (XRD) techniques. Tablets were pre-prepared by direct compression and evaluated for tablet characteristics, swelling studies, adhesion strength, percent of drug released, radiographic imaging studies and stability studies. The optimized formulations were then compared with the marketed formulations (Oflin $\mathrm{OD} \AA)$. The results showed that the prepared tablets showed good tablet characteristics, optimal swelling properties, and good adhesion strength with high detachment force. Most of the formulations including the optimized formulations following the Higuchi kinetics and drug release mechanism were found to be anomalous. The radiographic images prove that the tablets remain intact in structural integrity and form in the stomach for up to 24 hours. Short-term accelerated stability testing was carried out for the optimized 


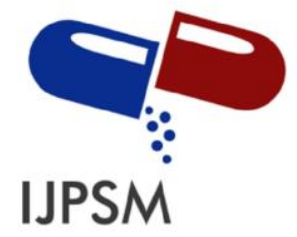

\section{$1^{\text {st }}$ Author et al., Int. Journal of Pharmaceutical Sciences and Medicine (IJPSM), Vol.1 Issue. 1, December- 2016, pg. 1-4}

formulation, and the results revealed the drug's content. in-vitro dissolution and all other parameters within acceptable limits. In the dissolution test, it was obtained a description of the drug release profile, namely Carbopol and HPMC are hydrophilic polymers. When the tablet containing this polymer comes into contact with water, it allows gradual hydration of the tablet matrix, which causes tablet swelling. When a tablet containing this polymer comes into contact with water, it allows gradual hydration of the tablet matrix, which causes tablet swelling. Water lowers the temperature of the glass transition from polymer to the experimental temperature. At this temperature, the glass polymer is converted to a spongy state. The mobility of the polymeric chain is enhanced under these circumstances. This condition supports the transport of water into the tablet and consequently the transport of the dissolved drug from the tablet core to the dissolution medium. Drug release from matrix tablets is determined by drug characteristics, delivery system and destination (drug release site). The drug content of each $400 \mathrm{mg}$ tablet and $900 \mathrm{ml}$ dissolution media were used for dissolution studies. Ofloxacin has a solubility of $76 \mathrm{mg} / \mathrm{mL}$ in $0.1 \mathrm{~N} \mathrm{HCl}$ at $25^{\circ} \mathrm{C}$. Maintaining sink conditions is essential during dissolution experiments for consistent and accurate measurement of dissolution rates. According to the United States Pharmacopoeia (USP, 2005), sink conditions are established when the saturation solubility is at least three times as much as the drug concentration in a dissolving medium. Thus, the sink condition can be maintained entirely. Dissolution and drug solubility studies cannot be the factors responsible for the delay in drug release from the study formulation. The inhibition of drug release from the formulation can be attributed to the nature of the polymer used in the formula. [23]

Literature study conducted by Kumar and Yagnesh on Solid Dispersion: An Approach to Increase the Solubility of Insoluble Drugs. This article reviews various preparation techniques for solid dispersions, the carriers used in solid dispersion formulations and solid dispersion pharmaceutical applications that can provide comprehensive knowledge on improving the solubility of insoluble drugs. Amorphous solid dispersion has provided an attractive alternative to overcome solubility limitations. Solid dispersion method is one of the effective approaches to achieve the goal of increasing the solubility of drugs that are difficult to dissolve in water. Increasing the oral bioavailability of water-insoluble drugs remains one of the most challenging aspects of drug development. Drug dissolution is a step in determining the rate of oral drug absorption which in turn can affect drug absorption in vivo. For increasing solubility in medicinal water, many techniques have been adopted since several decades and solid dispersion is one such technique. The use of solid dispersions for the development of the release rates and oral bioavailability of well water-insoluble drugs, with careful selection of carriers, is also feasible to delay or slow down the drug release pattern by formulating it into solid dispersions. [24]

Research Okonogi et al. conducted a study with the aim of increasing the dissolution rate of the water-saving drug, ofloxacin, with a solid substance dispersion system with urea and mannitol. Differential scanning calorimetry (DSC), X-ray powder diffraction analysis (PXRD) and infrared (IR) spectroscopy were performed to evaluate the physicochemical properties of the prepared solid dispersions. The dissolution rate of ofloxacin was significantly increased in the solid dispersions of urea and mannitol. Solubility studies showed a marked increase in the solubility of ofloxacin with an increase in urea concentration. The concentration of mannitol had no effect on the solubility of ofloxacin. The PXRD study revealed that the crystallinity of ofloxacin files decreased as the ratio of drug to carrier decreased. The results from the DSC and IR indicate that there is no drug-carrier interaction. [25]

Research by Raval et al. conducted research on increasing chlorzoxazone dissolution using cogrinding techniques. The aim of this study was to increase dissolution speed and processing parameters of BCS class II chlorzoxazone drug using cogrinding technique in the presence of different excipients as carriers. Materials and methods of this research are using drugs wrapped in various carriers such as polyethylene glycol (PEG 4000), hydroxypropyl methylcellulose (HPMC) E50LV, polyvinylpyrrolidone (PVP) K30, Kaolin and Neusilin US2 using a ball mill, PEG 4000 which increases the dissolution rate of the drug by carrying amorphization in a 1: 3 ratio. The coground mixture after 3 and 6 hours was evaluated for a wide variety of analytic, physicochemical and mechanical parameters. The analysis showed the conversion of chlorzoxazone from crystals to amorphous form after grinding with PEG 4000. The coground mixture as well as direct tablet compression showed a 2.5-fold increase in dissolution rate compared to the pure drug. Direct compressible tablets prepared from pure drug require large amounts of microcrystalline cellulose (MCC) during compression. The coground mixture and formulation were found to be stable in nature even after storage $\left(40^{\circ}\right.$ 


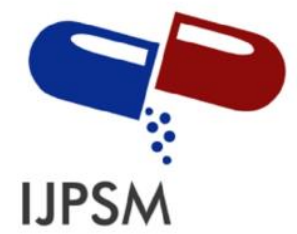

\section{$1^{\text {st }}$ Author et al., Int. Journal of Pharmaceutical Sciences and Medicine (IJPSM), Vol.1 Issue. 1, December- 2016, pg. 1-4}

C / 75\% relative humidity). This study concludes that cogrinding can be used successfully to increase the dissolution rate of water-insoluble drugs and hence bioavailability. [26]

\section{Conclusion}

Based on the results of journal analysis, it can be concluded that the use of poloxamer, PEG, and Urea polymers and the addition of chitosan can increase the dissolution rate of Ofloxacin in the solid dispersion system.

\section{References}

[1]. Alatas F, Nurono S, Asyarie S. Pengaruh konsentrasi PEG 4000 terhadap laju disolusi ketoprofen dalam sistem dispersi padat ketoprofen-PEG 4000. Majalah Farmasi Indonesia. 2006;17(2):57-62.

[2]. Zaini E, Putri VZ, Octavia MD, Ismed F. Peningkatan Laju Disolusi Dispersi Padat Amorf Genistein dengan PVP K30. Jurnal Sains Farmasi \& Klinis. 2017 Nov 15;4(1):67-72.

[3]. Cui Y, Zhang Y, Tang X. In vitro and in vivo evaluation of Ofloxacin sustained-release pellets. International journal of pharmaceutics. 2008 Aug 6;360(1-2):47-52.

[4]. Sagala RJ. Metode Peningkatan Kecepatan Disolusi Dikombinasi Dengan Penambahan Surfaktan. Jurnal Farmasi Galenika (Galenika Journal of Pharmacy)(e-Journal). 2019 Apr 2;5(1):84-92.

[5]. Wikarsa S, Samaria MF. Peningkatan Disolusi Nifedipin dari Mikrokristalnya yang Dibuat Melalui Pengendapan Antisolvent dengan Keberadaan Poloxamer 188 atau Natrium Lauril Sulfat. Acta Pharmaceutica Indonesia. 2012 Sep 28;37(3):110-115.

[6]. Sweetman SC, editor. Martindale: the complete drug reference. London: Pharmaceutical Press; 2009 Jun 29.

[7]. Wilson CO, Gisvold O, Block JH, Beale JM. Wilson and Gisvold's textbook of organic medicinal and pharmaceutical chemistry/edited by John H. Block, John M. Beale Jr. Philadelphia: Lippincott Williams \& Wilkins; 2004.

[8]. Dyaswara YC. Uji Mutu Fisik Tablet Dan Disolusi Terbanding Tablet Ofloxacin Generik Dengan Inovator (Doctoral dissertation, Universitas Setia Budi Surakarta).

[9]. Sharma A, Jain CP. Preparation and characterization of solid dispersions of carvedilol with PVP K30. Research in pharmaceutical sciences. 2010 Jan;5(1):49-56.

[10]. Pintu KD, Basudev S, Soumen R. Enhancement of dissolution rate and stability study of ofloxacin solid dispersion. Der Pharmacia Sinica. 2011;2(5):169-181.

[11]. Okonogi S, Puttipipatkhachorn S. Dissolution improvement of high drug-loaded solid dispersion. Aaps Pharmscitech. 2006 Jun 1;7(2):E148-153.

[12]. Saritha N, Jaya S. Preparation and evaluation of solid dispersions of Ofloxacin. World J. Pharmaceut. Res.. 2017 Oct $12 ; 6(16): 1116-1154$.

[13]. Ratnapuri PH, Suwaldi, Kharis A. Karakteristik Fisikokimia Dispersi Padat Ofloksasin Dengan Pembawa Peg 6000 Dalam Sistem Biner Dan Terner. Prosiding Seminar Nasional Kefarmasian, 2016 Oct;161-167.

[14]. Okonogi S, Sirithunyalung J, Sirithunyalig B, Wolschann P, Viernstein H. Effect of carrier types on the physicochemical and dissolution characteristics of ofloxacin solid dispersion. Scientia Pharmaceutica. 2002 Sep;70(3):309-316.

[15]. Urbaniak B, Milanowski B, Lulek J, Kokot ZJ. Study Of Ofloxacin Enantiomers Dissolution From Selected Solid Dosage Forms Using High-Performance Capillary Electrophoresis Method. Acta Polonia Pharmaceutica. 2017 May;74(3):955-968.

[16]. Mistry AK, Nagda CD, Nagda DC, Dixit BC, Dixit RB. Formulation and in vitro evaluation of ofloxacin tablets using natural gums as binders. Scientia Pharmaceutica. 2014 Jun;82(2):441-448.

[17]. Khalid S, Gauhar S, Rehman R, Fatima S. Post-market surveillance of different brands of Ofloxacin 200 mg tablets available in the local market of Karachi (Pakistan). Int J Pharm Pharm Sci. 2012;4(4):668-672.

[18]. Babu R J, Vidyadhara S, Basha A. Formulation And In Vitro Evaluation Of Ofloxacin As Floating Drug Delivery System Der Pharmacia Lettre. 2013;5(5):82-92.

[19]. Saigeethika S, Singhvi G. Formulation and evaluation of floating tablets of Ofloxacin. International Journal of Pharmaceutical Sciences and Research. 2012 Nov 1;3(11):4291-4296.

[20]. Baddam S, Bandari S, Chaithanya G. Formulation and evaluation of fast dissolving tablets of Ofloxacin by direct compression method. International research journal of pharmacy. 2013;4(11):79-86.

[21]. Awofisayo SO, Awofisayo OA, Eyen N, Udoh IE. Comparative assessment of the quality control measurements of multisource ofloxacin tablets marketed in Nigeria. Dissolution Technologies. 2010 May;1(17):20-25. 


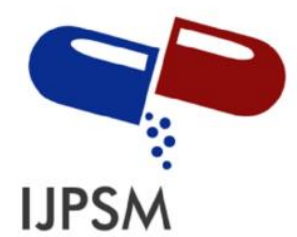

$1^{\text {st }}$ Author et al., Int. Journal of Pharmaceutical Sciences and Medicine (IJPSM), Vol.1 Issue. 1, December- 2016, pg. 1-4

[22]. Singh V, Sharma P, Jain A, Chaudhary J. In-Vitro Quality Assessment of Different Marketed Brands of Ofloxacin Tablets. Der Pharma Chemica. 2018; 10(5):65-68.

[23]. Gangurde HH, Chordiya MA, Tamizharasi S, Senthilkumaran K, Sivakumar T. Formulation and evaluation of sustained-release bioadhesive tablets of Ofloxacin using 32 factorial design. International journal of pharmaceutical investigation. $2011 \mathrm{Jul} ; 1(3): 148-156$.

[24]. Kumar SR, Yagnesh T. N S. Solid Dispersions: An Approach To Enhance Solubility Of Poorly Soluble Drugs. Indo American Journal of Pharmaceutical Research.2016 Jan;6(11):7036-7056.

[25]. Okonogi S, Oguchi T, Yonemochi E, Puttipipatkhachorn S, Yamamoto K. Improved dissolution of Ofloxacin via solid dispersion. International journal of pharmaceutics. 1997 Oct 24;156(2):175-180.

[26]. Raval MK, Patel JM, Parikh RK, Sheth NR. Dissolution enhancement of chlorzoxazone using grinding technique. International journal of pharmaceutical investigation. 2015 Oct;5(4):247-258.

\section{A Brief Author Biography}

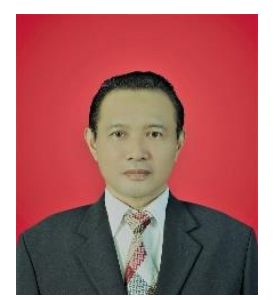

Prof. Dr. Harrizul Rivai, M.S., was born in Payakumbuh, West Sumatra, on 4 September 1953. His father is Rivai Said, and his mother is Saridahanum Syofyan. The Author obtained a Bachelor of Pharmacy from the Department of Pharmacy, Faculty of Mathematics and Natural Sciences, Padjajaran University, Bandung (1976), a Master of Science degree from the Bandung Institute of Technology (1984), and a Doctorate from the Department of Chemistry, Faculty of Mathematics and Natural Sciences, Andalas University, Padang (2011). Now the Author is a Professor and Researcher at the Faculty of Pharmacy, Andalas University, Padang. The Author also serves as Deputy Chair of Academic Affairs at the YPTIK Padang College of Pharmacy (STIFARM). The Author wrote the book "Principles of Chemical Examination" (Publisher UI-Press, 1995), translated the book "Pharmaceutical Statistics" (EGC Medical Book Publishers, 2010), and wrote "Chapter 4" in the book "Recent Research Advances in Biology Vol. 4 "(International Book Publisher, India, and United Kingdom, 2020). The Author has also written articles in various international journals in various science fields, such as chemistry, biology, and pharmacy. 